\title{
5-HT 2 Receptor Regulation of Extracellular GABA Levels in the Prefrontal Cortex
}

\author{
Walid M. Abi-Saab, M.D., Michael Bubser, Ph.D., Robert H. Roth, Ph.D., and Ariel Y. Deutch, Ph.D.
}

Monoamines, including both dopamine and serotonin, synapse onto prefrontal cortical interneurons. Dopamine has been shown to activate these GABAergic interneurons, but there are no direct data on the effects of serotonin on $G A B A$ release in the prefrontal cortex. We, therefore, examined the effects of the 5-HT $2 a / c$ agonist 1-(2,5-dimethoxy4-iodophenyl-2-aminopropane (DOI) on extracellular GABA levels in the prefrontal cortex of the rat. Local infusions of DOI dose-dependently increased cortical extracellular GABA levels. In addition, systemic DOI administration resulted in Fos protein expression in glutamic acid decarboxylase ${ }_{67}$-immunoreactive interneurons of the prefrontal cortex. These data indicate that serotonin, operating through a 5- $\mathrm{HT}_{2}$ receptor, acutely activates GABAergic interneurons in the prefrontal cortex. These data further suggest that there may be convergent regulation of interneurons by dopamine and serotonin in the prefrontal cortex. [Neuropsychopharmacology 20:92-96, 1999] (C) 1998 American College of Neuropsychopharmacology. Published by Elsevier Science Inc.
KEY WORDS: Fos; GABA; Interneuron; Microdialysis; Prefrontal cortex; Schizophrenia; Serotonin

Anatomical studies over the past decade have illuminated the synaptic organization of monoamine-containing axons and GABAergic interneurons in the cortex. Dopamine (DA) axons form synaptic specializations with interneurons in the prefrontal cortex (PFC) (Verney et al. 1991; Smiley and Goldman-Rakic 1993; Sesack et al. 1995). Consistent with this anatomical arrangement, DA acts through a $\mathrm{D}_{2}$-like DA receptor to increase extracellular GABA levels in the PFC of the rat (Grobin and Deutch 1998) and depolarizes PFC interneurons (Yang et al. 1997; Zheng et al. 1997). We have previ-

From the Departments of Psychiatry and Pharmacology (WMA-S, RHR), Yale University School of Medicine, New Haven, Connecticut; and Departments of Psychiatry and Pharmacology, and Center for Molecular Neuroscience (MB, AYD), Vanderbilt University School of Medicine, Nashville, Tennessee, USA.

Address correspondence to: Dr. A. Y. Deutch, Psychiatric Hospital at Vanderbilt, Suite 313, 1601 23rd Avenue South, Nashville, TN 37212, USA.

Received February 3, 1998; revised April 30, 1998; accepted May $5,1998$. ously found that acute administration of the atypical antipsychotic drug clozapine sharply decreases extracellular GABA levels in the PFC, and the typical antipsychotic drug (APD) haloperidol only weakly alters GABA levels (Bourdelais and Deutch 1994). The differences between the effects of the two APDs on GABA release in the PFC may be due to the potent 5-HT receptor antagonism of clozapine.

Recent anatomical data indicate that the major target of serotonin axons in the PFC is the interneuron (Smiley and Goldman-Rakic 1996). 5- $\mathrm{HT}_{2 \mathrm{a}}$ and 5- $\mathrm{HT}_{2 \mathrm{c}}$ mRNAs are expressed in PFC neurons, and immunohistochemical and in situ hybridization histochemical data indicate that the $5-\mathrm{HT}_{2 \mathrm{a}}$ receptor is localized to a subset of interneurons as well as pyramidal cells (Burnet et al. 1995; Willins et al. 1997; Jakab and Goldman-Rakic 1997).

The role of serotonin in regulating GABA release in the PFC has not been studied directly. Because interneurons in the PFC express $5-\mathrm{HT}_{2}$ receptors, we examined the ability of the 5- $\mathrm{HT}_{2 \mathrm{a} / \mathrm{c}}$ agonist 1-(2,5-dimethoxy-4iodophenyl-2-aminopropane; DOI) to alter extracellular GABA levels in the PFC, using in vivo microdialysis. In addition, in order to determine if DOI activates interneurons in the PFC, we examined the effects of DOI on 
Fos protein induction in GABAergic cells using immunohistochemical methods.

\section{METHODS}

Adult male Sprague-Dawley rats (Camm, Wayne, NJ, USA) were housed on a 12:12 light-dark cycle and had free access to food and water. Rats were surgically implanted with chronic in-dwelling guide cannulae into the PFC (coordinates AP +3.0 from bregma; L +2.2; DV -2.3; implanted $17^{\circ}$ from vertical [Paxinos and Watson 1986]). Five to seven days later, microdialysis probes (260 $\mu \mathrm{m}$ o.d.) with an exchange length of $3.0 \mathrm{~mm}$ were inserted into the PFC in awake rats, and the probes were perfused overnight $(0.2 \mu \mathrm{l} / \mathrm{min})$ with artificial cerebrospinal fluid (see Grobin and Deutch 1998). The next morning, the flow was increased to $2.0 \mu \mathrm{l} / \mathrm{min}$, and after a 60 -min equilibration period, dialysis samples were collected every $20 \mathrm{~min}$ from the freely moving rats. Five 20-min samples were collected for baseline determination, after which DOI $(5.0,50$, or $100 \mu \mathrm{m})$ was administered through the dialysis probe for 20 min, and the next seven dialysis samples were collected. Rats were sacrificed, and probe placements in the PFC were verified by examining cresyl violetstained coronal sections cut through the PFC.

Dialysis samples were analyzed by high-performance liquid chromatography (HPLC) with electrochemical detection, using precolumn derivatization with O-phthaldialdehyde (see Bourdelais and Kalivas 1991). Raw data (fmols / $\mu$ l dialysate) were analyzed for over-all significance by ANOVA with repeated measures on the time factor.

To examine the cellular targets of DOI, rats were injected subcutaneously with $5.0 \mathrm{mg} / \mathrm{kg}$ DOI or vehicle, and perfused 3 hours later with $4 \%$ paraformaldehyde. Sections were processed for immunohistochemical localization of $\mathrm{GAD}_{67}$ using a rabbit antibody (1:1000; Chemicon; Temuecula, CA, USA); a peroxidase-antiperoxidase method with diaminobenzidine as the chromogen was used, yielding a brown cytosolic reaction product. Sections were subsequently processed using an avidin-biotin immunoperoxidase method for demonstration of Fos-like immunoreactivity (-li), with diaminobenzidine in the presence of cobalt chloride and

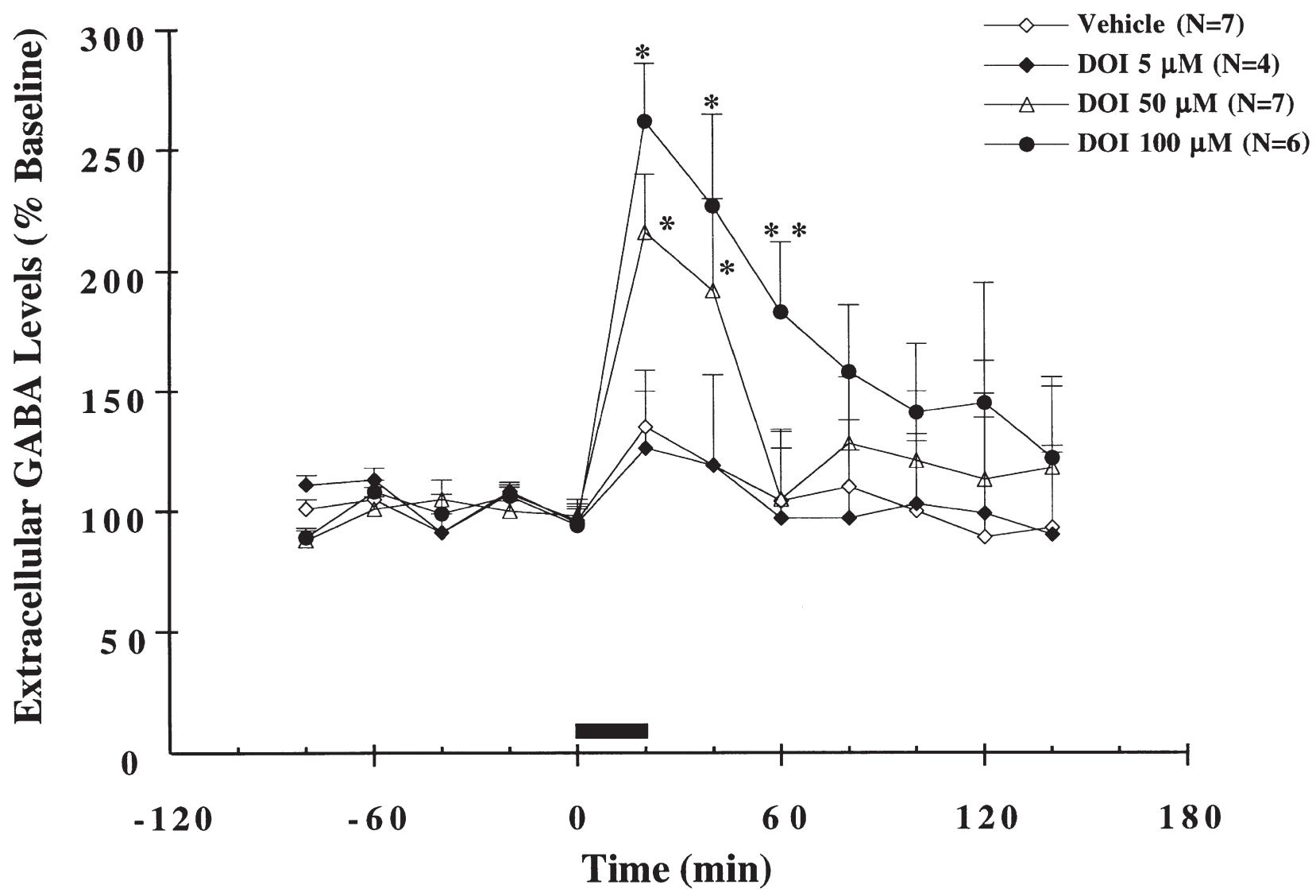

Figure 1. The effects of local administration of DOI on extracellular GABA levels in the PFC. DOI dose-dependently increased extracellular GABA levels. Data are shown as $\%( \pm \mathrm{SEM})$ change from baseline. ${ }^{*} p \leqslant .005 ;{ }^{* *} p \leqslant .05$, relative to vehicle-treated control values. 
nickel ammonium sulfate yielding black Fos-like immunoreactive nuclei that were clearly visibly against the brown cytosolic reaction product for $\mathrm{GAD}_{67} \mathrm{-li}$ (see Deutch et al. 1991); a sheep antibody directed against Fos (1:6000; Genosys; The Woodlands, TX, USA) was used. The number of Fos-li neurons in a defined area of the prelimbic/infralimbic cortices was first counted, and then the number of Fos-li neurons in $100 \mathrm{GAD}_{67}-\mathrm{li}$ neurons was counted to arrive at a percentage of interneurons expressing Fos. The numbers of Fos-li cells in the PFC of control and DOI-treated rats were compared using a $t$-test, and the percentage of interneurons expressing Fos-li in vehicle- and DOI-treated rats were compared using the Mann-Whitney U statistic.

\section{RESULTS}

Local PFC administration of the 5- $\mathrm{HT}_{2 \mathrm{a} / \mathrm{c}}$ agonist DOI significantly increased extracellular GABA levels in the PFC in a dose-dependent manner. Mean baseline GABA levels in the PFC were $38.3 \pm 3.9 \mathrm{fmols} / \mu \mathrm{l}$ (not corrected for probe recovery of $\approx 8 \%$ ). $5.0 \mu \mathrm{M}$ DOI administration did not alter extracellular GABA levels in the PFC, but the intermediate and high doses both increased extracellular GABA levels (see Figure 1).

Immunohistochemical examination revealed that administration of $5.0 \mathrm{mg} / \mathrm{kg}$ DOI significantly increased the number of Fos-li neurons in the PFC $(1.7 \pm 0.3$ Fos-li cells in vehicle-treated rats versus $35.0 \pm 9.5$ Fos-li cells in DOI-treated rats; $\mathrm{t}[4]=3.51, p \leqslant .05$ ). Double-labeling studies revealed Fos-li Nuclei in both GABAergic (GAD67-li) interneurons and in cells that did not exhibit $\mathrm{GAD}_{67}-\mathrm{li}$ and were thus considered pyramidal cells (Figure 2). DOI treatment significantly increased the percentage of GABAergic cells in the PFC that expressed Fos-li $(p \leqslant .05)$, with vehicle-treated animals expressing Fos-li in $4.3( \pm 1.4) \%$ of interneurons, as compared to DOI-treated animals expressing Fos-li in 12.3 $( \pm 1.7) \%$ of GABAergic neurons.

\section{DISCUSSION}

Acute DOI treatment increased extracellular GABA levels and increased Fos expression in GABAergic cells of the PFC. These data are consistent with the hypothesis that serotonin, acting through a 5-HT2 receptor, activates cortical interneurons.

The ability of DOI to increase extracellular GABA levels is most likely caused by release of the transmitter from interneurons. Basal extracellular GABA levels in the PFC are partly tetrodotoxin-sensitive under our conditions in the awake, freely moving animal (Bourdelais and Deutch 1994), suggesting that some of the GABA in the dialysate is derived from nontransmitter

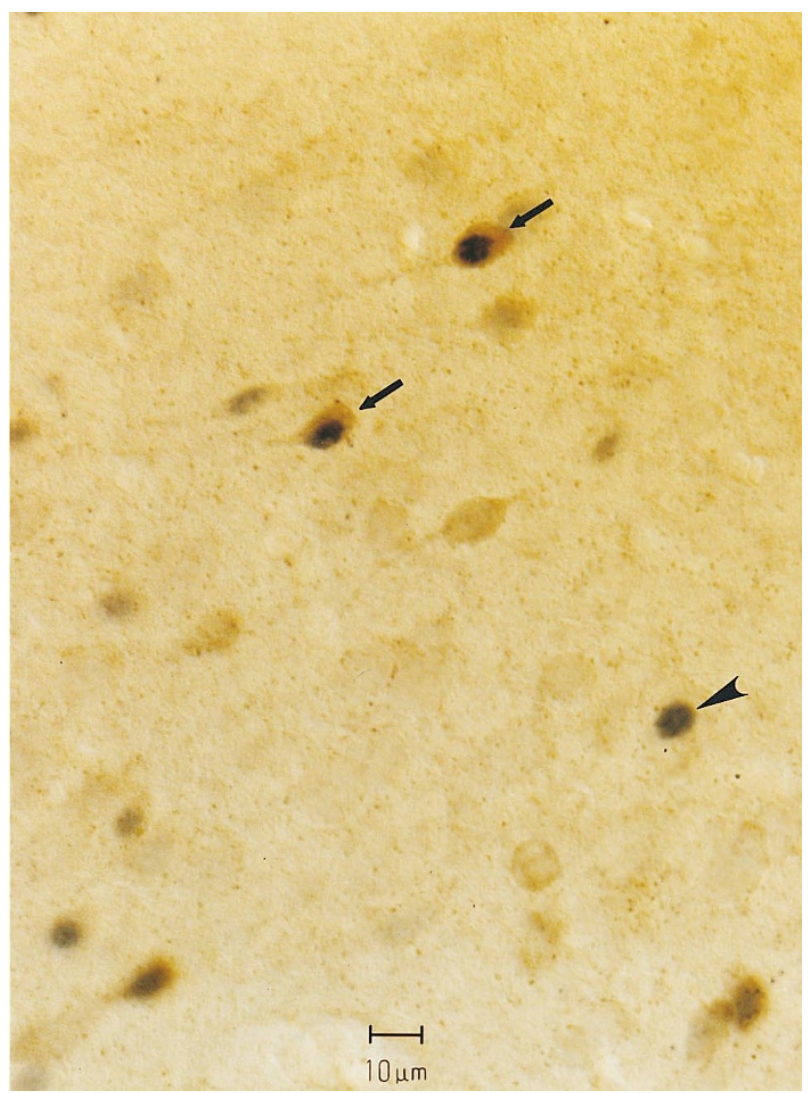

Figure 2. Photomicrograph of Fos-like immunoreactive nuclei (black reaction product) in $\mathrm{GAD}_{67}$-positive (small arrow) interneurons and $\mathrm{GAD}_{67}$-negative pyramidal cells (arrowhead). GAD 67 -li neurons that do not express Fos-li can also be seen.

pools of the amino acid. However, the DA agonistevoked increase in extracellular GABA is $>90 \%$ tetrodotoxin-sensitive (Grobin and Deutch 1998), suggesting that evoked GABA release is derived almost solely from the transmitter pool. This suggestion is consistent with previous data (Campbell et al. 1993).

Systemic administration of DOI increased the number of Fos-like immunoreactive neurons in the PFC, confirming the observation of Leslie et al. (1993) that DOI induces Fos expression in (uncharacterized) cortical neurons. We found that vehicle-treated rats rarely displayed Fos-li nuclei in $\mathrm{GAD}_{67}$-li cells, but in DOI-treated rats, Fos expression was observed in both interneurons and pyramidal cells. These findings are consistent with the dialysis data, and suggest that DOI specifically targets GABA interneurons as well as pyramidal cells. DOI does not induce Fos in all interneurons; further work will be necessary to determine the distinct population(s) of GABAergic interneurons that are affected.

It is unclear if the effect of DOI on GABAergic interneurons is direct or is mediated through activation of pyramidal cell collaterals. Electrophysiological data in 
the pyriform cortex indicate that DOI directly depolarizes interneurons (Marek and Aghajanian 1994). However, electrophysiological studies in the PFC suggest that the major effect of serotonin is on pyramidal cells (Aghajanian and Marek 1997). Because 5- $\mathrm{HT}_{2 \mathrm{a}}$ receptors are present on interneurons and pyramidal cells (Willins et al. 1997; Jakab and Goldman-Rakic 1997), DOI may exert both direct and indirect effects on interneurons. In view of the data indicating that the interneuron is the major target of serotonin terminals in the PFC, (Smiley and Goldman-Rakic 1996), it is conceivable that serotoninmediated synaptic transmission regulates GABAergic interneurons, and that nonjunctional ("paracrine") serotonergic transmission is more critically related to pyramidal cell activity.

DOI displays high affinities for both the $5-\mathrm{HT}_{2 \mathrm{a}}$ and $5-\mathrm{HT}_{2 \mathrm{c}}$ receptors. The former are expressed on interneurons and pyramidal cells (Willins et al. 1997; Jakab and Goldman-Rakic 1997), but the cellular localization of the $5-\mathrm{HT}_{2 \mathrm{c}}$ receptor in the PFC is not known. Further work using specific $5-\mathrm{HT}_{2 \mathrm{a}}$ and $5-\mathrm{HT}_{2 \mathrm{c}}$ antagonists will unravel the relative contributions of these receptors to serotonergic regulation of GABAergic interneurons.

The ability of DOI to increase extracellular GABA levels in the PFC is consistent with the hypothesis that serotonin regulates cortical interneurons, and suggests that GABAergic mechanisms may indirectly contribute to the mechanisms of action of atypical APDs. In the rat pyriform cortex, where $5-\mathrm{HT}_{2 \mathrm{a}}$ activation depolarizes interneurons (Sheldon and Aghajanian 1991; Marek and Aghajanian 1994), atypical APDs potently block serotonin-mediated effects (Gellman and Aghajanian 1994). Acute administration of the atypical APD clozapine sharply decreases PFC GABA levels (Bourdelais and Deutch 1994), consistent with the high $5-\mathrm{HT}_{2}: \mathrm{D}_{2}$ affinity ratio of clozapine (Meltzer et al. 1989).

Our data indicate that serotonin, operating through a $5-\mathrm{HT}_{2}$ receptor, activates GABAergic interneurons in the PFC. We have recently reported that DA agonists, operating through a $\mathrm{D}_{2}$ receptor, also increase extracellular GABA levels (Grobin and Deutch 1998). Thus, DA and serotonin may coordinately regulate PFC interneurons, similar to the situation observed in the pyriform cortex (Gellman and Aghajanian 1993). The high $5-\mathrm{HT}_{2 \mathrm{a}}: \mathrm{D}_{2}$ affinity ratio of clozapine and other putative atypical APDs (Meltzer et al. 1989) fits well with a coordinate regulation of interneurons in the PFC by serotonin and dopamine.

\section{ACKNOWLEDGMENTS}

We thank A. Chistina Grobin for her help, advice, and encouragement, Cheryl D. Young for helpful discussions, and Dorothy Cameron for technical assistance. This work was sup- ported by a VA Psychiatry Research Fellowship (WMA-S), a NARSAD Young Investigator Award (WMA-S), and grants MH-14092 (RHR), MH-57995 (AYD), and MH-45124 (AYD).

\section{REFERENCES}

Aghajanian GK, Marek GJ (1997): Serotonin induces excitatory postsynaptic potentials in apical dendrites of neocortical pyramidal cells. Neuropharmacology 36:589599

Bourdelais AJ, Deutch AY (1994): The effects of haloperidol and clozapine on extracellular GABA levels in the prefrontal cortex of the rat: An in vivo microdialysis study. Cerebr Cort 4:69-77

Bourdelais AJ, Kalivas PW (1991): High sensitivity HPLC assay for GABA in brain dialysates. J Neurosci Meth 39:115-121

Burnet PW, Eastwood SL, Lacey K, Harrison PJ (1995): The distribution of $5-\mathrm{HT}_{1 \mathrm{a}}$ and $5-\mathrm{HT}_{2 \mathrm{a}}$ receptor mRNA in human brain. Brain Res 676:157-168

Campbell K, Kalen P, Wictorin K, Lundberg C, Mandel RJ, Bjorklund A (1993): Characterization of GABA release from intrastriatal striatal transplants: Dependence upon host-derived afferents. Neuroscience 53:403-415

Deutch AY, Lee MC, Gillham MH, Cameron D, Goldstein M, Iadorola MJ (1991): Stress selectively increases Fos protein in dopamine neurons innervating the prefrontal cortex. Cerebr Cort 1:273-292

Gellman RL, Aghajanian GK (1993): Pyramidal cells in piriform cortex receive a convergence of inputs form monoamine activated GABAergic interneurons. Brain Res 600:63-73

Gellman RL, Aghajanian GK (1994): Serotonin 2 receptormediated excitation of interneurons in piriform cortex: Antagonism by atypical antipsychotic drugs. Neuroscience 58:515-525

Grobin AC, Deutch AY (1998): Dopaminergic regulation of extracellular GABA levels in the prefrontal cortex. J Pharm Exp Ther 285:350-357

Jakab RL, Goldman-Rakic PS (1997): 5-Hydroxytryptamine 2 a serotonin receptors in the primate cerebral cortex: Possible site of action of hallucinogenic and antipsychotic drugs in pyramidal cell apical dendrites. Proc Natl Acad Sci USA 95:735-740

Leslie RA, Moorman JM, Coulson A, Grahame-Smith DG (1993): Serotonin $2 / 1 \mathrm{C}$ receptor activation causes a localized expression of the immediate-early gene c-fos in rat brain: Evidence for involvement of dorsal raphe nucleus projection fibers. Neuroscience 53:457-463

Marek GJ, Aghajanian GK (1994): Excitation of interneurons in piriform cortex by serotonin (5-HT): Blockade by MDL100,907, a highly selective 5-HT2a antagonist. Eur J Pharmacol 259:137-141

Meltzer HY, Matsubara S, Lee J-C (1989): Classification of typical and atypical antipsychotic drugs on the basis of D-1, D-2, and serotonin ${ }_{2} \mathrm{pK}_{\mathrm{i}}$ values. J Pharmacol Exp Ther 251:238-246

Paxinos G, Watson C (1986): The Rat Brain in Stereotaxic Coordinates, 2nd ed. San Diego, CA, Academic Press 
Sesack SR, Snyder CL, Lewis DA (1995): Axon terminals immunolabeled for dopamine or tyrosine hydroxylase synapse on GABA-immunoreactive dendrites in rat and monkey cortex. J Comp Neurol 363:264-280

Sheldon P, Aghajanian GK (1991): Excitatory responses to serotonin (5-HT) in neurons of the rat piriform cortex: Evidence for mediation by 5 -HT1C receptors in pyramidal cells and 5-HT2 receptors in interneurons. Synapse 9:208-218

Smiley JF, Goldman-Rakic PS (1993): Heterogeneous targets of dopamine synapses in monkey prefrontal cortex demonstrated by serial section electron microscopy: A laminar analysis using the silver enhanced diaminobenzidinesulfide (SEDS) immunolabeling technique. Cerebr Cort 3:223-238

Smiley JF, Goldman-Rakic PS (1996): Serotonergic axons in monkey prefrontal cerebral cortex synapse predomi- nantly on interneurons as demonstrated by serial section electron microscopy. J Comp Neurol 367:431-443

Verney C, Alvarez C, Geffard M, Berger B (1991): Ultrastructural double-labeling study of dopamine terminals and GABA-containing neurons in rat anteromedial cerebral cortex. Eur J Neurosci 2:960-972

Willins DL, Deutch AY, Roth BL (1997): Serotonin 5- $\mathrm{HT}_{2 \mathrm{~A}}$ receptors are expressed on pyramidal cells and interneurons in the rat cortex. Synapse 27:79-82

Yang CR, Seamans JK, Goreleva N (1997): Mechanisms of dopamine (DA) modulation of GABAergic inputs to rat layer V-VI pyramdial prefrontal cortical (PFC) neurons in vitro. Soc Neurosci Abstr 23:1771

Zheng P, Bunney BS, Shi W-X (1997): Electrophysiological characterization and effect of dopamine on visually identified nonpyramidal neurons in the prefrontal cortex. Soc Neurosci Abstr 23:1212 